\title{
7
}

\section{MÉXICO: ENTRE LA PANDEMIA, EL MELODRAMA Y EL CRECIMIENTO DE LOS SISTEMAS DE VOD}

DOI: https://doi.org/10.7764/obitel.21.S.9

\section{Autores:}

Gabriela Gómez Rodríguez http://orcid.org/0000-0002-2078-1671, Darwin Franco Migues http://orcid.org/0000-0003-2979-2956

Agradecemos a Guillermo Orozco Gómez quien estuvo al frente de Obitel-México por 15 años, por toda su generosidad y enseñanzas.

\section{Introducción}

A nivel Latinoamérica, México fue uno de los países más afectados por la pandemia que ocasionó el coronavirus y la enfermedad que este causa, la COVID-19, al registrar más de 2 millones de casos positivos y más de 206 mil muertes ${ }^{1}$.

Por ello, millones de mexicanos se encontraron de un día a otro confinados en casa, 24 horas al día. Muchos tuvieron que salir a trabajar, pero otros más debieron permanecer en sus hogares. Esto implicó un total reto para las familias, sus dinámicas de convivencia cambiaron, sus rutinas y las interacciones entre cada uno.

Una de las dinámicas que tuvieron muchas familias fue ver la televisión abierta y contenidos vía streaming. El cierre de actividades y la obligación para quedarnos todos en casa, obligó de alguna mane- 
ra a consumir más contenidos, no solo de televisión abierta, sino vía plataformas de VoD. Algunos datos señalan que más de seis millones de personas miraron el Canal de las Estrellas (Televisa) en el horario estelar así como los servicios de SVoD han tenido mayor demanda durante la pandemia, pues se duplicó la tasa de crecimiento anual en suscripciones, pasando de $9,0 \%$ a $18,2 \%$.

La industria de producción de contenidos audiovisuales se vio ante retos mayúsculos para poder transmitir y producir productos; la caída en los ingresos publicitarios afectó los presupuestos de las producciones. Las televisoras, así como las empresas de OTT se vieron ante el reto de retener audiencias y ganar suscriptores, y poder contar con un catálogo amplio.

Por otra parte, al estar confinados en casa, millones de personas pudieron consumir contenidos vía $\mathrm{SVoD}$ en múltiples dispositivos y en diferentes horarios, en el momento y cuando ellos desearan. Sin duda alguna, la pandemia por Covid-19 está marcada por el uso y consumo de más tecnología y contenidos digitales, pero también, por un mayor crecimiento de la televisión.

Parte de este incremento en el visionado de la televisión abierta se debió a que las clases presenciales se tornaron no sólo virtuales, sino también televisivas, pues el Gobierno de México firmó, el 3 de agosto de 2020, un convenio con Televisa, TV Azteca, Grupo Imagen y Grupo Multimedios para que de manera conjunta apoyaran el Plan de Regreso a Clases del Ciclo Escolar 2020-2021, al facilitar la transmisión del programa "Aprende en Casa (I y II)", el cual estuvo dirigido a 30 millones de estudiantes de 16 grados escolares del sistema de educación básica (preescolar, primaria y secundaria), quienes tomaron clases mediante lecciones televisivas.

Este acuerdo, que inicialmente se aseguró era de buena voluntad, implicó un gasto de 450 millones de pesos tan sólo para el periodo del 24 de agosto al 18 de diciembre de 2020, y esto únicamente por la transmisión de los 1.550 contenidos que se generaron.

En agosto de ese año, Canal Once lanzó la licitación para la producción de contenidos educativos para la Secretaría de Educa- 
ción Pública (SEP), la cual se consideraba la licitación más grande que haya lanzado ese canal. La licitación se desahogó en 17 días. La empresa ganadora debía tener la capacidad de operar servicios para 900 a 2.300 personas, trasladar a 2.240 personas, dos foros propios para producción y 150 técnicos, para cambiar turnos cada ocho horas. Finalmente, el Canal 11 contrató por 51.5 millones de pesos, a nueve empresas para el programa "Aprende en Casa II".

En el plano comercial y debido a la pandemia, Televisa lanzó la estrategia \#TelevisaTeAcompaña en sus diferentes negocios con programación especial sobre el Covid-19, para transmitirlos a través de TV Abierta y de paga (Izzy y Sky). A esta estrategia se sumó la campaña "Mucho Ojo con el Coronavirus", transmitiendo información sobre salud, higiene y medidas preventivas.

Información que, igualmente, fue retomada en algunas ficciones nacionales como La Rosa de Guadalupe, la cual fue de las únicas producciones junto con Como dice el Dicho (ambas de Televisa) que de manera abierta tomaron a la pandemia como parte de su trama narrativa.

\section{El contexto audiovisual de México en 2020}

\subsection{La televisión abierta en México}

Cuadro 1. Cadenas/canales nacionales de televisión abierta en México

\begin{tabular}{|c|c|}
\hline Cadenas/canales privados (9) & Cadenas/canales públicos (4) \\
\hline $\begin{array}{c}\text { Televisa (Canales 2, 5, 9 y Foro } \\
\text { TV) }\end{array}$ & Once TV (Canal 11 y 11.1) \\
\hline $\begin{array}{c}\text { TV Azteca (Canales 1, 7, ADN4O } \\
\text { y }+ \text { ) }\end{array}$ & Conaculta (Canal 22) \\
Imagen Televisión (Canal 3) & Canal 14 (Canal 14) \\
\hline \multicolumn{2}{|c|}{ TOTAL DE CADENAS TELEVISIVAS = 6 } \\
TOTAL DE CANALES TELEVISIVOS $=\mathbf{1 3}$ \\
\hline
\end{tabular}

Fuente: Obitel México. 
Aunque se había anunciado que la alternancia en el gobierno federal implicaría una democratización en la televisión abierta nacional, no se han lanzado ni repuesto las licitaciones para una cuarta cadena nacional que había quedado desierta en 2015; lo que sí se ha instaurado de mejor manera es el uso de los canales espejo de las cadenas de televisión ya existentes; fue a través de las señales espejo de Televisa, TV Azteca y Grupo Imagen que se transmitieron las clases del programa "Aprend $\epsilon$ en Casa"; las únicas cadenas nacionales públicas que sí transmitieror las clases escolares fueron Canal Once, Canal 14 y Canal 22.

Gráfico 2: Géneros y horas transmitidos en la programación de $\mathbf{T V}^{2}$

\begin{tabular}{|c|c|c|}
\hline $\begin{array}{c}\text { Géneros } \\
\text { transmitidos }\end{array}$ & $\begin{array}{c}\text { Horas de } \\
\text { exhibición }\end{array}$ & $\mathbf{\%}$ \\
\hline Información & 21657 & 15 \\
\hline Ficción & 18310 & 12 \\
\hline Entretenimiento & 44040 & 30 \\
\hline Deporte & 15524 & 10 \\
\hline Educativo & 35460 & 24 \\
\hline Político & 3980 & 3 \\
\hline Otros & 8768 & 6 \\
\hline Religioso & 550 & 1 \\
\hline TOTAL & 148289 & $\mathbf{1 0 0 , 0}$ \\
\hline
\end{tabular}

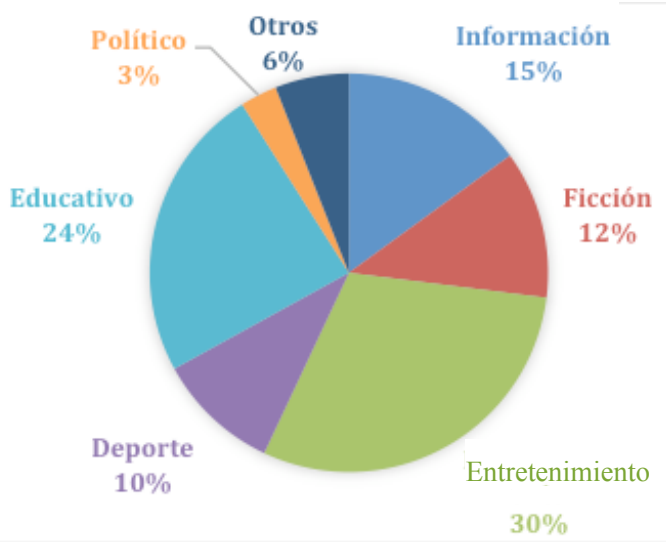

Fuente: Obitel México.

Un elemento a destacar es que en este año se incrementó el número de horas de contenido educativo debido al convenio que el Gobierno de México realizó con las cadenas nacionales comerciales (Televisa, TV Azteca e Imagen) para usar sus canales espejos para la transmisión de las clases por televisión que tuvieron que darse en el sistema de educación básica mexicano a causa de la pandemia de COVID-19 que suspendió las clases presenciales. 


\subsection{La TV de pago y plataformas VoD en México}

\section{Cuadro 2. Cadenas de televisión de pago en México}

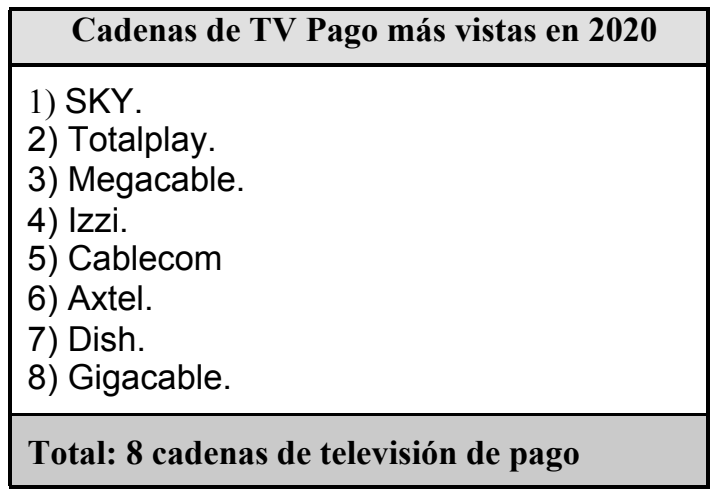

Fuente: Obitel México.

La penetración de internet de Banda Ancha, junto con la múltiple oferta de servicios de OTT's a nivel mundial, han provocado que exista una fuerte caída de los suscriptores a los servicios de televisión de paga. Esto, aunado a la pandemia, provocó aún más la baja de abonados. No obstante, en México, los suscritos a estos servicios de televisión de paga aumentaron en un 6,7\% durante 2020 .

A las empresas que ofrecen contenidos de TV de paga, les ha funcionado vender paquetes que ofrecen contenidos de TV satelital o por cable, más internet de banda ancha y telefonía. Siendo las empresas de Grupo Televisa (Sky, Izzi) las de mayor penetración (64,7\%); le siguen Megacable (15,9\%), Dish-MVS (12,3\%) y Total Play 5,3\%3.

3 Datos de diciembre de 2019 proporcionados por Statista: https://es.statista.com/estadisticas/984810/distribucion-por-proveedor-del-mercado-de-television-por-cable-mexico/ 


\section{Cuadro 3. El VoD en México}

\begin{tabular}{|l|l|}
\hline \multicolumn{1}{|c|}{$\begin{array}{c}\text { Principales plataformas de VoD } \\
\text { activas en 2020 }\end{array}$} & Total \\
\hline $\begin{array}{l}\text { Netflix (Netflix) } \\
\text { Disney+(Disney) } \\
\text { Dish Móvil (Dish), } \\
\text { Amazon Prime (Amazon) } \\
\text { Movistar+ (Telefónica) }\end{array}$ & $\mathbf{1 8}$ \\
Blim (Televisa) & \\
Apple TV (Apple) & \\
Cinépolis Klic (Cinépolis) & \\
Claro-Video (Claro Video). & \\
HBO Go (HBO) & \\
Pluto TV (ViacomCBS). & \\
Paramount+ (Paramount Picture). & \\
Acorn-TV & \\
Crunchyroll & \\
Curiosity stream & \\
Fox Premium & \\
Fox play & \\
Tubi & \\
\hline Total de platafomas VoD & $\mathbf{1 8}$ \\
\hline
\end{tabular}

Fuente: Obitel México.

\subsection{Productoras independientes de ficción televisiva}

En México, las productoras independientes son piezas muy importantes para las plataformas de VoD y las cadenas de televisión. En los últimos años sus producciones han sido éxitos en plataformas de SVoD y sin duda su participación va a la alza. Encontramos que en 2020 las productoras más activas fueron: Noc Noc Cinema que produjo para Netflix La Casa de las Flores $3^{a}$ temporada; Lemon Studios, que en 2020 realizó la serie Control Z. BTF media ha producido para Disney, TV Azteca, Netflix, Amazon Prime, Net Geo, entre otras. Entre sus más recientes producciones está Maradona "sueño bendito" a transmitirse a finales de 2021 .

Por otra parte, la productora Argos Comunicación (encabezada por Epigmenio Ibarra) ha colaborado para TV Azteca, Telemundo, Netflix, Imagen Televisión, Disney Channel entre otras cadenas (entre 
sus producciones se encuentran Ingobernable, El señor de los Cielos, etc.). Según su CEO, Epigmenio Ibarra, la empresa ha despegado, por lo que ganan una visión más global y un manejo del lenguaje más universal en sus producciones. En esta casa productora utilizan cada vez más el big data para construir historias, en lo que se conoce como data oriented content ${ }^{4}$. La producción realizada este año fue Oscuro Deseo, para Netflix. Por su parte, Estudios Teleméxico (de Fox TeleColombia) realizó para Claro-Video Promesas de Campaña. Mientras que Caponeto produjo para Netflix Desenfrenadas.

\subsection{Fuentes de financiamiento del sector audiovisual}

El año 2020 no fue nada bueno para las televisoras, pues la pandemia también afectó sus ingresos por concepto de publicidad. En reportes de otros años hemos venido sosteniendo que los ingresos vía publicidad han ido a la baja cada año. En los primeros nueve meses de 2020 Televisa y TV Azteca perdieron 8 mil 122.7 millones de pesos (cerca de 400 millones de dólares). Sin duda, las empresas privadas más importantes en México van perdiendo publicidad frente a las plataformas digitales. Otra de las razones de esta baja es el recorte en la partida presupuestal del gobierno, por concepto de publicidad oficial, y la caída de anunciantes ante la pandemia mundial.

El otro lado de la moneda, con un enorme crecimiento, lo recibieron las plataformas de streaming. Según Forbes, Netflix sumó 15.8 millones de usuarios en 2020, cuando en 2019 reportamos en este anuario 6 millones 783 mil cuentas activas. Es decir, durante la pandemia, han crecido en más del cien por ciento, las suscripciones para esa empresa.

4 Estudios Tele México. 


\subsection{Políticas de comunicación}

La enseñanza vía los canales de televisión regresó durante la pandemia, como estrategia del gobierno, como señalamos al inicio de este capítulo, debido a la pandemia por Covid-19. El 3 agosto de 2020, ante el incremento de casos y el riesgo de clases presenciales, el presidente López Obrador dio el anuncio de que el sistema educativo sería a distancia, a través de cuatro televisoras privadas con el fin de llegar a más de 30 millones de estudiantes de los niveles básicos. Para ello, se firmó un acuerdo por parte de la Secretaría de Educación y las televisoras. Las transmisiones fueron los siete días de la semana. Por esta transmisión, el gobierno pagó a las televisoras 450 millones de pesos (22 millones de dólares).

La prolongación de la pandemia al primer semestre de 2021, obligó al gobierno a crear "Aprende en Casa III", el cual ahora lo realiza Altán Redes -empresa mexicana responsable de diseñar, desplegar, operar y comercializar la Red Compartida, la Red para Todos (red estatal que brinda servicios de telecomunicaciones)-, y que sigue teniendo el apoyo de Canal Once para la generación de contenidos y de las televisoras para su transmisión y retransmisión.

\subsection{Infraestructura de conectividad digital y móvil}

Según datos del Censo de Población y Vivienda 2020 (INEGI, 2020), México cuenta con poco más de 126 millones de habitantes, siendo la edad media promedio 29 años. Es decir, México sigue siendo un país con población joven. Entre 2010 (cuando se aplicó el anterior Censo en el país) y 2020, en México la disponibilidad de teléfonos celulares en las viviendas creció de $65,1 \%$ a $87,5 \%$. Internet en los hogares de 21,3 a 51,3\%, mientras que las líneas telefónicas fijas descendieron de $43,2 \%$ a 37,5\%. Como podemos leer en estos datos, la internet ha ido creciendo en los hogares, así como los celulares, mientras que la telefonía fija va a la baja. La televisión sigue siendo un medio muy importante en las casas. Entre 2010 y 2020, la disponi- 
bilidad de la TV bajó solo 2 puntos (de $92,6 \%$ a 91,1\%), y un $43 \%$ de las viviendas disponen de TV de paga. Según datos arrojados en este Censo, hay una gran brecha digital entre la Ciudad de México (como el poseer una computadora) y otros estados del interior (en el sureste de la nación). Esto producto de las profundas desigualdades que imperan en el país desde hace décadas. La penetración de internet en el país para 2020 es de 80,6 millones de personas, siendo las poblaciones rurales las que menor acceso tienen a la red, y aún más de 40 millones de mexicanos sin acceso a esta.

\section{Análisis del Año: la Ficción de Estreno Nacional e Iberoameri- cana en la TV abierta}

Tabla 1. Ficciones exhibidas en $\mathbf{2 0 2 0}$

\begin{tabular}{|c|c|}
\hline $\begin{array}{l}\text { TÍTULOS INÉDITOS NACIONALES - } 13 \\
\text { Televisa - } 11 \text { títulos nacionales } \\
\text { 1. Vencer el miedo (Serie) } \\
\text { 2. Rubi (Serie) } \\
\text { 3. Te doy la Vida (Telenovela) } \\
\text { 4. La Mexicana y el Güero (Telenovela) } \\
\text { 5. Imperio de mentiras (Telenovela). } \\
\text { 6. Quererlo todo (Telenovela). } \\
\text { 7. Como dice el Dicho } 7 \text { (Dramatizado) } \\
\text { 8. La Rosa de Guadalupe } 13 \text { (Dramatizado). } \\
\text { 9. El Dragón: el regreso del guerrero (Serie). } \\
\text { 10. Esta Historia me Suena } 2 \text { (Serie) } \\
\text { 11. Vencer el Desamor (Telenovela) } \\
\text { TV Azteca - } \mathbf{2} \text { títulos nacionales } \\
\text { 12. La Bandida } 2 \text { (Serie). } \\
\text { 13. Lo que Callamos las Mujeres (Dramatizado) } \\
\text { Imagen TV- } 0 \text { títulos nacionales } \\
\text { Canal Once- } 0 \\
\text { Canal títulos nacionales } \\
\text { 0 títulos nacionales }\end{array}$ & $\begin{array}{l}\text { TÍTULOS IMPORTADOS INÉDITOS OBITEL -8 } \\
\text { Televisa - } 6 \text { títulos } \\
\text { 14. Preso No. I (Serie- EUA) } \\
\text { 15. El final del paraíso (Telenovela - Colombia/EUA). } \\
\text { 16. La Esclava Blanca (Serie- Brasil) } \\
\text { 17. Jesús (Telenovela-Brasil) } \\
\text { 18. Betty en NY (Serie - Colombia/EUA). } \\
\text { 19. Sin senos sí hay paraíso (Telenovela - } \\
\text { Colombia/EUA). } \\
\text { Imagen TV-1 título } \\
\text { 20. Dulce ambición (Telenovela - Brasil) } \\
\text { Canal 22 - } 1 \text { títulos } \\
\text { 21. El tiempo entre costuras (Serie - España) } \\
\text { TÍTULOS IMPORTADOS INÉDITOS NO } \\
\quad \text { OBITEL- } 4 \\
\text { Imagen TV- } 4 \text { títulos importados inéditos no } \\
\text { OBITEL } \\
\text { 22. Pecado original (Telenovela - Turquía). } \\
\text { 23. Omer sueños robados (Serie - Turquía). } \\
\text { 24. Mar negro (Telenovela - Turquía) } \\
\text { 25. Tierra Amarga (Telenovela -Turquía) }\end{array}$ \\
\hline
\end{tabular}




\begin{tabular}{|l|l|}
\hline TÍTULOS INÉDITOS NACIONALES & TÍTULOS REPOSICIONES- 9 \\
Televisa - 9 títulos nacionales \\
26. Mañana es para Siempre (Telenovela -México) \\
27. Soy tu Dueña (Telenovela -México) \\
& 28. Corazón Indomable (Telenovela -México) \\
& 29. Destilando Amor (Telenovela -México) \\
& 30. La que no Podía Amar (Telenovela -México) \\
& 31. Hoy voy a Cambiar (Serie -México) \\
& 32. Silvia Pinal, Frente a Ti (Serie -México) \\
& 33. Que Pobres tan Ricos (Telenovela -México) \\
& 34. Corona de Lágrimas (Telenovela -México) \\
& 35. La Rosa de Guadalupe (Unitario- Televisa) \\
& \\
& TOTAL DE TÍTULOS INÉDITOS NACIONALES: 13 \\
& TOTAL DE TÍTULOS INÉDITOS OBITEL: 8 \\
& TOTAL DE TÍTULOS INÉDITOS \\
& (NACIONAL Y OBITEL): 21 \\
\hline
\end{tabular}

Fuente: Obitel México.

A diferencia del 2019, en 2020 se estrenaron 10 títulos menos; la razón es la suspensión temporal y/o definitiva de la producción de diversas ficciones que optaron por retomar las grabaciones hasta que existieran condiciones más favorables para evitar contagios de COVID-19 entre el elenco y la producción.

Esto ocasionó que, más que en otros años, existieran varias reposiciones de títulos que habían sido ya estrenados; esta estrategia para colocar ficciones en pantalla resultó redituable en términos de rating, pues títulos como: La que no Podía Amar (2011), Soy tu Dueña (2010) y Destilando Amor (2007) -estas últimas protagonizadas por la ex primera dama de México, la actriz Angélica Rivera- se colocaron entre las ficciones más vistas en 2020, desplazando a los títulos de estreno, esto a pesar de ser transmitidas en un horario no estelar. 
Tabla 2: La Ficción de Estreno en 2020: México

\begin{tabular}{|l|c|c|c|c|c|c|}
\hline \multicolumn{1}{|c|}{ País } & Títulos & $\mathbf{\%}$ & $\begin{array}{c}\text { Capítulos/ } \\
\text { Episodios }\end{array}$ & $\mathbf{\%}$ & Horas & $\%$ \\
\hline NACIONAL (total) & $\mathbf{1 3}$ & $\mathbf{6 2 , 0}$ & $\mathbf{9 2 1}$ & $\mathbf{5 1 , 0}$ & $\mathbf{9 0 6 : 2 0 : 0 0}$ & $\mathbf{5 1 , 0}$ \\
\hline PAíSES OBITEL (total) & $\mathbf{8}$ & $\mathbf{3 8 , 0}$ & $\mathbf{8 9 2}$ & $\mathbf{4 9 , 9}$ & $\mathbf{8 8 4 : 0 0 : 0 0}$ & $\mathbf{4 9 , 0}$ \\
\hline Argentina & 0 & 0,0 & 0 & 0,0 & $0: 00: 00$ & 0,0 \\
\hline Brasil & 3 & 14,0 & 463 & 52,0 & $459: 30: 00$ & 52,0 \\
\hline Chile & 0 & 0,0 & 0 & 0,0 & $0: 00: 00$ & 0,0 \\
\hline Colombia & 3 & 14,0 & 374 & 42,0 & $371: 00: 00$ & 42,0 \\
\hline España & 1 & 5,0 & 11 & 1,0 & $10: 20: 00$ & 1,0 \\
\hline EE.UU. (producción hispana) & 1 & 5,0 & 44 & 5,0 & $43: 50: 00$ & 5,0 \\
\hline México* & 13 & 62,0 & $\mathbf{9 2 1}$ & $\mathbf{5 , 0}$ & $\mathbf{9 0 6}: 20: 00$ & $\mathbf{5 1 , 0}$ \\
\hline Perú & 0 & 0,0 & 0 & 0,0 & $0: 00: 00$ & 0,0 \\
\hline Portugal & 0 & 0,0 & 0 & 0,0 & $0: 00: 00$ & 0,0 \\
\hline Uruguay & 0 & 0,0 & 0 & 0,0 & $0: 00: 00$ & 0,0 \\
\hline Venezuela & 0 & 0,0 & 0 & 0,0 & $0: 00: 00$ & 0,0 \\
\hline COPRODUCCIONES (total) & $\mathbf{0}$ & $\mathbf{0 , 0}$ & $\mathbf{0}$ & $\mathbf{0 , 0}$ & $\mathbf{0 : 0 0 : 0 0}$ & $\mathbf{0 , 0}$ \\
\hline Coproducciones mexicanas $* *$ & $\mathbf{0}$ & $\mathbf{0 , 0}$ & $\mathbf{0}$ & $\mathbf{0 , 0}$ & $\mathbf{0 : 0 0 : 0 0}$ & $\mathbf{0 , 0}$ \\
\hline $\begin{array}{l}\text { Coproducciones entre países } \\
\text { OBITEL }\end{array}$ & $\mathbf{0}$ & $\mathbf{0 , 0}$ & $\mathbf{0}$ & $\mathbf{0 , 0}$ & $\mathbf{0 : 0 0 : 0 0}$ & $\mathbf{0 , 0}$ \\
\hline TOTAL GENERAL & $\mathbf{2 1}$ & $\mathbf{1 0 0 , 0}$ & $\mathbf{1 , 8 1 3}$ & $\mathbf{1 0 0 , 0}$ & $\mathbf{1 , 7 9 0 : 2 0 : 0 0}$ & $\mathbf{1 0 0 , 0}$ \\
\hline
\end{tabular}

Fuente: Obitel México.

A causa de la baja de títulos por la pandemia, en este año se redujo el número de capítulos y horas de la ficción nacional de estreno, pero no fue así para la ficción iberoamericana de estreno que para este año incrementó sus horas en pantalla casi al doble respecto de 2019.

En 2020, no se registraron coproducciones entre México y algunos otros países Obitel. 
Tabla 3. Formatos de la ficción nacional e iberoamericana

\begin{tabular}{|l|c|c|c|c|c|c|c|c|c|c|c|c|}
\hline \multirow{2}{*}{ Formato } & \multicolumn{4}{|c|}{ Nacionales } & \multicolumn{5}{c|}{ Ibero-americanos } \\
\cline { 2 - 14 } & Títulos & $\mathbf{\%}$ & $\mathbf{C} / \mathbf{E}$ & $\mathbf{\%}$ & $\mathbf{H}$ & $\mathbf{\%}$ & $\begin{array}{c}\text { Títul } \\
\mathbf{0 S}\end{array}$ & $\mathbf{\%}$ & $\mathbf{C} / \mathbf{E}$ & $\mathbf{\%}$ & $\mathbf{H}$ & $\%$ \\
\hline Telenovela & 5 & 38,4 & 430 & 47,0 & $426: 00: 00$ & 47,0 & 4 & 50,0 & 652 & 73,1 & $646: 10: 00$ & 73,0 \\
\hline Serie & 5 & 38,4 & 255 & 28,0 & $249: 20: 00$ & 27.4 & 4 & 50,0 & 240 & 26,9 & $238: 00: 00$ & 27,0 \\
\hline Miniserie & 0 & 0,0 & 0 & 0,0 & $0: 00: 00$ & 0,0 & 0 & 0,0 & 0 & 0,0 & $0: 00: 00$ & 0,0 \\
\hline Telefilme & 0 & 0,0 & 0 & 0,0 & $0: 00: 00$ & 0,0 & 0 & 0,0 & 0 & 0,0 & $0: 00: 00$ & 0,0 \\
\hline Unitario & 3 & 23,0 & 236 & 25,0 & $231: 00: 00$ & 25,6 & 0 & 0,0 & 0 & 0,0 & $0: 00: 00$ & 0,0 \\
\hline Docudrama & 0 & 0,0 & 0 & 0,0 & $0: 00: 00$ & 0,0 & 0 & 0,0 & 0 & 0,0 & $0: 00: 00$ & 0,0 \\
\hline $\begin{array}{l}\text { Otros (soap } \\
\text { opera, etc.) }\end{array}$ & 0 & 0,0 & 0 & 0,0 & $0: 00: 00$ & 0,0 & 0 & 0,0 & 0 & 0,0 & $0: 00: 00$ & 0,0 \\
\hline Total & $\mathbf{1 3}$ & $\mathbf{1 0 0 , 0}$ & $\mathbf{9 2 1}$ & $\mathbf{1 0 0 , 0}$ & $\mathbf{9 0 6 : 2 0 : 0 0}$ & $\mathbf{1 0 0 , 0}$ & $\mathbf{8}$ & $\mathbf{1 0 0 , 0}$ & $\mathbf{8 9 2}$ & $\mathbf{1 0 0 , 0}$ & $\mathbf{8 8 4 : 1 0 : 0 0}$ & $\mathbf{1 0 0 , 0}$ \\
\hline
\end{tabular}

Elaboración de OBITEL con datos nacionales proporcionados por Nielsen Ibope México, S.A. de C.V. Software MSS TV, Base "Rating regular 5 dominios +Dish. Total de Programación televisiva durante 2020.

En cuanto al formato, en 2020 la producción de series se mantuvo a la alza tanto en títulos nacionales como iberoamericanos; aunque en el caso de los nacionales sigue existiendo un amplio consumo de los dramatizados unitarios La Rosa de Guadalupe y Como Dice el Dicho; ambos se colocaron entre las cinco ficciones más vistas en el año.

También es para destacar la drástica baja en las horas producidas de telenovelas para 2020, pues en el 2019 fueron 750 horas mientras que para 2020 fueron 249 horas, es decir, un 66\% menos. La razón de esta disminución es que varias de las producciones tuvieron que parar sus grabaciones producto de la pandemia, lo cual a la larga también implicó una reducción de sus capítulos, lo que -a su vez- redujo el número de horas de transmisión. 
Tabla 4. Los 10 títulos más vistos en la televisión abierta ${ }^{5}$

\begin{tabular}{|c|l|c|c|c|c|c|c|c|}
\hline \multicolumn{2}{|c|}{ Título } & Canal & Productora & $\begin{array}{c}\text { Formato } \\
\text { /Género }\end{array}$ & $\begin{array}{c}\text { No de } \\
\text { cap./ep. } \\
(\mathbf{2 0 2 0})\end{array}$ & $\begin{array}{c}\text { Franja } \\
\text { horaria }\end{array}$ & Rating & Share \\
\hline 1 & $\begin{array}{l}\text { Te doy la } \\
\text { Vida }\end{array}$ & Canal 2 & Televisa & Telenovela & 81 & Tarde & 18,94 & 29,62 \\
\hline 2 & Rubi & Canal 2 & Televisa & Serie & 27 & Prime & 17,71 & 25,73 \\
\hline $\begin{array}{l}\text { La Rosa de } \\
\text { Guadalupe } \\
13\end{array}$ & Canal 2 & Televisa & Unitario & 88 & Tarde & 17,60 & 26,86 \\
\hline 4 & $\begin{array}{l}\text { Vencer el } \\
\text { Miedo }\end{array}$ & Canal 2 & Televisa & Serie & 46 & Tarde & 16,51 & 27,63 \\
\hline 5 & $\begin{array}{l}\text { Como Dice } \\
\text { el Dicho }\end{array}$ & Canal 2 & Televisa & Unitario & 155 & Tarde & 16,22 & 27,88 \\
\hline $\begin{array}{l}\text { El Dragón: } \\
\text { el Regreso } \\
\text { de un } \\
\text { Guerrero }\end{array}$ & Canal 2 & Televisa & Serie & 82 & Prime & 15,42 & 23,26 \\
\hline 7 & $\begin{array}{l}\text { Vencer el } \\
\text { Desamor }\end{array}$ & Canal 2 & Televisa & Telenovela & 93 & Tarde & 14,10 & 20,99 \\
\hline 8 & $\begin{array}{l}\text { Quererlo } \\
\text { todo }\end{array}$ & Canal 2 & Televisa & Telenovela & 39 & Tarde & 13,98 & 28,13 \\
\hline & $\begin{array}{l}\text { Esta } \\
\text { Historia } \\
\text { me Suena 2 }\end{array}$ & Canal 2 & Televisa & Unitario & 38 & Tarde & 13,14 & 22,21 \\
\hline & $\begin{array}{l}\text { La } \\
\text { Mexicana y } \\
\text { el Güero }\end{array}$ & Canal 2 & Televisa & Telenovela & 126 & Prime & 12,36 & 18,89 \\
\hline
\end{tabular}

Elaboración de OBITEL con datos nacionales proporcionados por Nielsen Ibope México, S.A. de C.V. Software MSS TV, Base "Rating regular 5 dominios +Dish. Total de Programación televisiva durante 2020.

Es para destacar que en 2020, los ratings subieron respecto a 2019, año en que la ficción más vista alcanzó 18.94 puntos; esto implica un aumento de alrededor de un punto en relación al año 2019, lo cual resalta, pues la tendencia era la disminución, en promedio, de uno a dos puntos de rating por año.

Este año, a diferencia de los tres anteriores, La Rosa de Guadalupe no fue la ficción más vista, aunque sí quedó en tercer lugar; sin em-

5 Los diez títulos más vistos se refieren únicamente a aquellas ficciones que se estrenaron en 2020, por lo cual este top ten puede no coincidir con las diez ficciones más vistas durante el 2020 en la televisión abierta nacional. 


\begin{tabular}{|c|c|c|c|c|c|c|c|}
\hline \multirow{2}{*}{\multicolumn{2}{|c|}{ Títulos }} & \multirow{3}{*}{\begin{tabular}{|r|} 
Canal \\
Canal 2 \\
\end{tabular}} & \multicolumn{2}{|c|}{ Rating Género \% } & \multicolumn{3}{|c|}{ Nivel socioeconómico \% } \\
\hline & & & \multirow{2}{*}{$\begin{array}{c}\text { Mujeres } \\
9,1 \\
\end{array}$} & \multirow{2}{*}{$\begin{array}{c}\text { Hombres } \\
4,9 \\
\end{array}$} & \multirow{2}{*}{$\begin{array}{c}\mathbf{A B} \\
7,8 \\
\end{array}$} & \multirow{2}{*}{$\begin{array}{c}\mathbf{C} \\
15,9 \\
\end{array}$} & \multirow{2}{*}{$\begin{array}{c}\text { DE } \\
23,5 \\
\end{array}$} \\
\hline 7 & Vencer el Desamor & & & & & & \\
\hline 8 & Quererlo Todo & Canal 2 & 8,2 & 4,0 & 7,7 & 15,6 & 20,6 \\
\hline 9 & Esta Historia me Suena 2 & Canal 2 & 7,5 & 4,0 & 7,4 & 10,7 & 20,9 \\
\hline 10 & La Mexicana y el Güero & Canal 2 & 7,8 & 4,4 & 7,0 & 11,8 & 23,1 \\
\hline \multicolumn{2}{|r|}{ Títulos } & Canal & 4 a 12 & 13 a 18 & 19 a 29 & 30 a 44 & $45+$ \\
\hline 1 & Te doy la Vida & Canal 2 & 9,0 & 8,9 & 5,5 & 9,6 & 11,5 \\
\hline 2 & Rubi & Canal 2 & 8,5 & 8,0 & 6,7 & 8,6 & 9,9 \\
\hline 3 & La Rosa de Guadalupe 13 & Canal 2 & 9,1 & 8,6 & 5,8 & 7,8 & 10,2 \\
\hline 4 & Vencer el Miedo & Canal 2 & 8,1 & 6,7 & 5,3 & 6,8 & 8,6 \\
\hline 5 & Como dice el Dicho & Canal 2 & 8,5 & 7,4 & 5,7 & 6,6 & 9,4 \\
\hline 6 & $\begin{array}{l}\text { El dragón: el Regreso de } \\
\text { un Guerrero }\end{array}$ & Canal 2 & 7,1 & 6,1 & 5,0 & 6,8 & 8,9 \\
\hline 7 & Vencer el Desamor & Canal 2 & 7,2 & 6,8 & 4,9 & 7,0 & 8,9 \\
\hline 8 & Quererlo Todo & Canal 2 & 6,5 & 5,4 & 4,5 & 6,1 & 8,3 \\
\hline 9 & Esta Historia me Suena 2 & Canal 2 & 5,8 & 5,4 & 4,8 & 5,8 & 7,0 \\
\hline 10 & La Mexicana y el Güero & Canal 2 & 6,5 & 6,8 & 4,3 & 5,9 & 8,0 \\
\hline
\end{tabular}

Elaboración de OBITEL con datos nacionales proporcionados por Nielsen Ibope México, S.A. de C.V. Software MSS TV, Base "Rating regular 5 dominios +Dish. Total de Programación televisiva durante 2020.

Como ha sido una constante en los últimos cinco años, el perfil de quien consume ficción en México es una mujer mayor a los 45 años que pertenece a los niveles socioeconómicos medios y bajos.

Sin embargo, la condición pandémica que orilló a la población a quedarse en casa tuvo un impacto en el visionado de ficción, ya que todos los grupos socioeconómicos aumentaron su audiencia. El que más fue el grupo DE (de más bajo ingreso socioeconómico) pues en 2019 para el programa de mayor rating tenía 20,14; es decir, aumentó ese grupo cinco puntos rating su visionado en televisión abierta. 
bargo, a la preferencia por dramatizados unitarios se suma Esta historia me suena que centra su dinámica en torno a problemáticas juveniles que se desarrollan a través de una canción. Este formato es similar a la ficción La vida es una canción, unitario que produjo TV Azteca en el año 2004. También cabe destacar el unitario Como dice el Dicho, que va ganando audiencia; este programa es producido por Televisa.

La ficción más vista en 2020 fue Te doy la vida, cuya trama principal gira en torno al diagnóstico de leucemia de un menor para el cual la única alternativa es la donación de médula de un padre biológico que no conoce y la historia de amor que se presenta entre su padre biológico y su madre adoptiva; esta fue una adaptación de un título chileno con el mismo nombre. En México fue la telenovela con mayor rating este año, transmitida en horario vespertino, no en un horario prime time como era la tendencia.

Tabla 5. Perfil de audiencia de los 10 títulos más vistos: género, edad, nivel socioeconómico

\begin{tabular}{|l|l|l|c|c|c|c|c|}
\hline \multirow{2}{*}{\multicolumn{2}{|c|}{ Títulos }} & \multirow{2}{*}{ Canal } & \multicolumn{3}{c|}{ Rating Género \% } & \multicolumn{3}{c|}{ Nivel socioeconómico \% } \\
\cline { 4 - 8 } & & Mujeres & Hombres & AB & C & DE \\
\hline $\mathbf{1}$ & Te doy la Vida & Canal 2 & 10,8 & 7,4 & 10,3 & 19,5 & 26,7 \\
\hline $\mathbf{2}$ & Rubi & Canal 2 & 10,7 & 6,0 & 10,5 & 18,7 & 25,0 \\
\hline $\mathbf{3}$ & $\begin{array}{l}\text { La Rosa de } \\
\text { Guadalupe 13 }\end{array}$ & Canal 2 & 10,2 & 5,4 & 9,3 & 17,6 & 29,0 \\
\hline $\mathbf{4}$ & Vencer el Miedo & Canal 2 & 9,5 & 5,1 & 8,9 & 16,5 & 24,7 \\
\hline $\mathbf{5}$ & Como dice el Dicho & Canal 2 & 9,47 & 5,1 & 9,8 & 15,9 & 25,1 \\
\hline & $\begin{array}{l}\text { El Dragón: el } \\
\text { Regreso de } \\
\text { un guerrero }\end{array}$ & Canal 2 & 8,4 & 5,6 & 8,5 & 16,0 & 22,3 \\
\hline
\end{tabular}




\begin{tabular}{|c|c|c|c|c|c|c|c|}
\hline \multirow{2}{*}{\multicolumn{2}{|c|}{ Títulos }} & \multirow{3}{*}{\begin{tabular}{|r|} 
Canal \\
Canal 2 \\
\end{tabular}} & \multicolumn{2}{|c|}{ Rating Género \% } & \multicolumn{3}{|c|}{ Nivel socioeconómico \% } \\
\hline & & & \multirow{2}{*}{$\begin{array}{c}\text { Mujeres } \\
9,1 \\
\end{array}$} & \multirow{2}{*}{$\begin{array}{c}\text { Hombres } \\
4,9 \\
\end{array}$} & \multirow{2}{*}{$\begin{array}{c}\mathbf{A B} \\
7,8 \\
\end{array}$} & \multirow{2}{*}{$\begin{array}{c}\mathbf{C} \\
15,9 \\
\end{array}$} & \multirow{2}{*}{$\begin{array}{c}\text { DE } \\
23,5 \\
\end{array}$} \\
\hline 7 & Vencer el Desamor & & & & & & \\
\hline 8 & Quererlo Todo & Canal 2 & 8,2 & 4,0 & 7,7 & 15,6 & 20,6 \\
\hline 9 & Esta Historia me Suena 2 & Canal 2 & 7,5 & 4,0 & 7,4 & 10,7 & 20,9 \\
\hline 10 & La Mexicana y el Güero & Canal 2 & 7,8 & 4,4 & 7,0 & 11,8 & 23,1 \\
\hline \multicolumn{2}{|r|}{ Títulos } & Canal & 4 a 12 & 13 a 18 & 19 a 29 & 30 a 44 & $45+$ \\
\hline 1 & Te doy la Vida & Canal 2 & 9,0 & 8,9 & 5,5 & 9,6 & 11,5 \\
\hline 2 & Rubi & Canal 2 & 8,5 & 8,0 & 6,7 & 8,6 & 9,9 \\
\hline 3 & La Rosa de Guadalupe 13 & Canal 2 & 9,1 & 8,6 & 5,8 & 7,8 & 10,2 \\
\hline 4 & Vencer el Miedo & Canal 2 & 8,1 & 6,7 & 5,3 & 6,8 & 8,6 \\
\hline 5 & Como dice el Dicho & Canal 2 & 8,5 & 7,4 & 5,7 & 6,6 & 9,4 \\
\hline 6 & $\begin{array}{l}\text { El dragón: el Regreso de } \\
\text { un Guerrero }\end{array}$ & Canal 2 & 7,1 & 6,1 & 5,0 & 6,8 & 8,9 \\
\hline 7 & Vencer el Desamor & Canal 2 & 7,2 & 6,8 & 4,9 & 7,0 & 8,9 \\
\hline 8 & Quererlo Todo & Canal 2 & 6,5 & 5,4 & 4,5 & 6,1 & 8,3 \\
\hline 9 & Esta Historia me Suena 2 & Canal 2 & 5,8 & 5,4 & 4,8 & 5,8 & 7,0 \\
\hline 10 & La Mexicana y el Güero & Canal 2 & 6,5 & 6,8 & 4,3 & 5,9 & 8,0 \\
\hline
\end{tabular}

Elaboración de OBITEL con datos nacionales proporcionados por Nielsen Ibope México, S.A. de C.V. Software MSS TV, Base "Rating regular 5 dominios +Dish. Total de Programación televisiva durante 2020.

Como ha sido una constante en los últimos cinco años, el perfil de quien consume ficción en México es una mujer mayor a los 45 años que pertenece a los niveles socioeconómicos medios y bajos.

Sin embargo, la condición pandémica que orilló a la población a quedarse en casa tuvo un impacto en el visionado de ficción, ya que todos los grupos socioeconómicos aumentaron su audiencia. El que más fue el grupo DE (de más bajo ingreso socioeconómico) pues en 2019 para el programa de mayor rating tenía 20,14; es decir, aumentó ese grupo cinco puntos rating su visionado en televisión abierta. 


\section{Monitoreo VoD 2020}

La pandemia tuvo repercusiones positivas para la industria del SVoD. Como reportamos previamente en este documento, las suscripciones a Netflix en México crecieron más del cien por ciento (creció de 6 millones 783 mil cuentas a 15,8 millones en 2020), lo cual también ha tenido un punto de realce con la llegada de nuevos servicios, siendo el más esperado Disney Plus.

\subsection{Mercado de plataformas de VoD}

La tan anunciada llegada Disney Plus a México se dio el 17 de noviembre, y en su primer día de lanzamiento, colapsó en algunas áreas del país, por la saturación de la plataforma. Se le considera un real competidor para Netflix y para muestra lo siguiente: México es el tercer país con mayor número de descargas de la APP Disney Plus, después de Estados Unidos y Brasil (2,2 millones de descargas en el mes de su lanzamiento), lo que lo ubica en la segunda plataforma de SVoD con mayor cantidad de suscripciones en México.

Los ingresos generados por la App de Disney + en México en noviembre de 2020 sumaban 350.200 dólares $^{6}$. Se prevé que Disney realizará 21 producciones en México en 2021. Por otra parte, según datos de The CIU, Prime Video cuenta con 918 mil cuentas, le sigue Claro-Video con 418 mil, al igual que HBO-Go, y por último se encuentra BLIM, con 234.600 cuentas $^{7}$. Se pronostica para junio de 2021 el lanzamiento de Star +, la nueva oferta de Walt Disney Studios, y en ese mismo mes la llegada de HBO Max. En cuanto a inversiones en producciones en México, Netflix invirtió 200 millones de dólares

6 https:/elceo.com/tecnologia/mexico-el-tercer-pais-con-mas-descargas-de-la-app-dedisney-plus/

7 https://www.xataka.com.mx/streaming/disney-plus-llegara-a-mexico-prime-video-tieneque-preocuparse-marvel-star-wars-subio-al-segundo-lugar-streaming 
en producciones en México y se espera para 2021 un gasto en 300 millones.

\subsection{Análisis del VoD en 2020: la ficción de estreno nacional e ibe- roamericana}

En el 2020, Claro-Video incrementó las producciones nacionales (seis) a diferencia de una sola producción que transmitió en el 2019 (la serie Claramente). Encontramos en sus contenidos series protagonizadas por Eugenio Derbéz, quien debido a la pandemia tuvo que quedarse en su casa, -como la gran mayoría-, y supo aprovechar esta situación para producir una serie desde ahí, compartiendo lo que su familia y él vivían.

Claro-Video ha apostado por producir series históricas, como Orgullo México, así como por el género de comedia como en Manual para Galanes y Herederos por Accidente. Por su parte, Netflix sigue prefiriendo producir contenidos que abordan temas basados en hechos reales, como lo hizo con la serie Historia de un Crimen. La búsqueda cuya historia impactó a una gran parte de la sociedad mexicana en el año 2010. Así como temas que abordan contenidos sobre terror (Diablero), crimen (Oscuro Deseo), y contenidos cuyos protagonistas son jóvenes: La Casa de las Flores (3a. y última temporada) y Desenfrenadas. Mientras que Prime-Video parece preferir producir contenidos con temas dirigidos a los jóvenes: De Brutas Nada y Cómo sobrevivir soltero. Mientras que Blim, este año tuvo solo una producción, en su quinta temporada 40 y 20.

Se estima que en 2020 las principales plataformas de Video on Demand (sin contar en este reporte la recién llegada Disney Plus), Netflix, Claro-Video, Blim y Prime-Video obtuvieron ganancias superiores a los 200 millones de dólares. 
Un reporte del Instituto Federal de Telecomunicaciones (IFT), que aplicó una encuesta a usuarios que contaban con servicios de OTT, indicó que un 84 por ciento de estos están suscritos en Netflix ${ }^{8}$.

Las series de acción y aventuras son una parte importante del panorama de las series originales digitales. Muchos de los servicios de transmisión más grandes compiten en este campo, con algunas de las series más importantes de este género que impulsan suscripciones.

En los últimos meses, la participación de las series de Amazon Prime Video han aumentado del 9,5\% en agosto al 20,8\% en septiembre de 2020. El original de Amazon más demandado entre julio y septiembre en México fue The Boys (Informe Parrot Analytics).

Tabla 6. Ficciones nacionales e iberoamericanas exhibidas en 2020 en sistemas de VoD

\begin{tabular}{|c|c|c|}
\hline $\begin{array}{l}\text { TÍTULOS } \\
\text { NACIONALES DE } \\
\text { ESTRENO }\end{array}$ & $\begin{array}{l}\text { TÍTULOS } \\
\text { IBEROAMERICANOS DE } \\
\text { ESTRENO }\end{array}$ & COPRODUCCIONES \\
\hline $\begin{array}{l}\text { Netflix - } 6 \text { títulos } \\
\text { nacionales } \\
\text { 1. La Casa de las Flores } \\
\text { (3a temporada) (serie). } \\
\text { 2. Control Z (serie). } \\
\text { 3. Diablero 2 (serie). } \\
\text { 4. Oscuro Deseo (serie). } \\
\text { 5. Historia de un crimen. } \\
\text { La búsqueda (serie). } \\
\text { 6. Desenfrenadas (serie). } \\
\text { Claro-Video-6 títulos } \\
\text { nacionales } \\
\text { 1. DesHecho en casa } \\
\text { (serie)- } \\
\text { 2. Orgullo México (serie). } \\
\text { 3. Herederos por } \\
\text { Accidente (serie). } \\
\text { 4. Promesas de Campaña } \\
\text { (serie). } \\
\text { 5. Manual para Galanes } \\
\text { (serie). }\end{array}$ & $\begin{array}{l}\text { Netflix - } 14 \text { títulos } \\
\text { iberoamericanos } \\
\text { 1. Elite } 2 \text { (serie-España) } \\
\text { 2. Selena: La Serie (serie - } \\
\text { Estados Unidos). } \\
\text { 3. Las Chicas del Cable } 5 \text { (serie } \\
\text {-España). } \\
\text { 4. Alguien tiene que morir } \\
\text { (miniserie -Estados Unidos). } \\
\text { 5. Altar Mar } 3 \text { (serie -España). } \\
\text { 6. Valeria (serie -España). } \\
\text { 7. Los favoritos de Midas (serie } \\
\text {-España). } \\
\text { 8. El desorden que dejas (serie - } \\
\text { España). } \\
\text { 9. 100 dias para Enamorarnos } \\
\text { (serie -Estados Unidos). } \\
\text { 10. 3\% } 4 \text { (serie -Brasil). } \\
\text { 11. Reality Z (serie -Brasil). } \\
\text { 12. Siempre bruja (serie - } \\
\text { Colombia). } \\
\text { 13. Espectros (serie -Brasil). }\end{array}$ & $\begin{array}{l}\text { Netflix - } 0 \text { títulos } \\
\text { Prime-Video- } 0 \text { títulos } \\
\text { Claro TV- } 0 \text { títulos }\end{array}$ \\
\hline
\end{tabular}




\begin{tabular}{|c|c|c|}
\hline $\begin{array}{l}\text { TÍTULOS } \\
\text { NACIONALES DE } \\
\text { ESTRENO }\end{array}$ & $\begin{array}{l}\text { TÍTULOS } \\
\text { IBEROAMERICANOS DE } \\
\text { ESTRENO }\end{array}$ & COPRODUCCIONES \\
\hline \multicolumn{3}{|l|}{$\begin{array}{l}\text { Claro - Video - } 6 \text { títulos } \\
\text { nacionales }\end{array}$} \\
\hline 6. Reto Tokio 2020 (serie). & $\begin{array}{l}\text { 14. Omnisciente (serie -Brasil). } \\
\text { 15. Narcos } 2 \text { (serie-Estados }\end{array}$ & \\
\hline $\begin{array}{l}\text { Prime-Video- } 4 \text { títulos } \\
\text { nacionales }\end{array}$ & & \\
\hline 1. De Brutas Nada (serie). & Prime-Video- 3 títulos & \\
\hline 2. Cómo sobrevivir soltero & iberoamericanos & \\
\hline $\begin{array}{l}\text { (serie). } \\
\text { 4. El Candidato (serie). }\end{array}$ & $\begin{array}{l}\text { 1. Patria (serie-España). } \\
\text { 2. Caronte (serie-España). }\end{array}$ & \\
\hline 5. Ana (serie) & 3. El Cid (serie-España). & \\
\hline Blim- 1 título nacional & Claro TV - 1 título & \\
\hline 1. 40 y 20 (5ta. temporada) & iberoamericano & \\
\hline (serie). & 1. Monte Olivos (serie-España). & \\
\hline Total: 17 & Total: 19 & Total: 0 \\
\hline \multicolumn{3}{|l|}{ TOTAL GENERAL: 36} \\
\hline
\end{tabular}

Fuente: Obitel México.

En lo nacional fueron 16 títulos de estreno, siendo las series el formato más socorrido; aunque en este año se habían anunciado más producciones mexicanas de parte de Netflix, muchas de estas se postergaron para los años 2021 y 2022; la compañía norteamericana planea hacer de México, el epicentro de sus producciones ficcionales, pues en enero con ese objetivo mudó su sede creativa y de producción a nuestro país.

Es para destacar que con los datos extraídos de reportes de Parrot Analytics (The Global Television Demand Report, 2020) arrojan que en las 20 ficciones con mayor audiencia en México en los SVoD aparecen dos producciones nacionales e iberoamericanas de estreno: Narcos 2 (Netflix) en el sitio número dos y La Casa de las Flores ( $3^{\mathrm{a}}$ temporada) en el $12 \mathrm{o}$. lugar. 
Tabla 7. La ficción de estreno en 2020 en VoD: países de origen

\begin{tabular}{|l|r|r|}
\hline \multicolumn{1}{|c|}{ País } & Títulos & \multicolumn{1}{c|}{$\%$} \\
\hline NACIONAL (total) & $\mathbf{1 7}$ & $\mathbf{4 7 , 0}$ \\
\hline PAÍSES OBITEL (total) & $\mathbf{1 9}$ & $\mathbf{5 3 , 0}$ \\
\hline Argentina & 0 & 0,0 \\
\hline Brasil & 4 & 21,0 \\
\hline Chile & 0 & 0,0 \\
\hline Colombia & 1 & 3,0 \\
\hline España & 10 & 52,0 \\
\hline EE.UU. (producción hispana) & 4 & 21,0 \\
\hline México* & 17 & 100,0 \\
\hline Perú & 0 & 0,0 \\
\hline Portugal & 0 & 0,0 \\
\hline Uruguay & 0 & 0,0 \\
\hline Venezuela & 0 & 0,0 \\
\hline COPRODUCCIONES (total) & $\mathbf{0}$ & $\mathbf{0 , 0}$ \\
\hline Coproducciones mexicanas ** & $\mathbf{0}$ & 0,0 \\
\hline Coproducciones entre países OBITEL & $\mathbf{0}$ & 0,0 \\
\hline TOTAL GENERAL & $\mathbf{3 5}$ & $\mathbf{1 0 0 , 0}$ \\
\hline
\end{tabular}

Fuente: Obitel México.

Es para subrayar que en los $\mathrm{SVoD}$, las producciones españolas dominan la escena con 10 de los 18 títulos de estreno en 2020, seguido de las producciones brasileñas con cuatro títulos, esto en cuanto a los títulos iberoamericanos. 


\section{Ficción y participación de las audiencias en entornos digitales}

\subsection{Propuestas de expansión digital}

Las plataformas de SVoD promueven desde las redes sociales digitales los contenidos que producen. Aunque en algunas series manejan su propia cuenta en redes sociales, existe un manejo "global" para promover los contenidos del catálogo de las plataformas de la región latinoamericana. En el caso de las producciones realizadas en México, se promueven también en twitter a través de @Netflix Latinoamérica. La cuenta tiene 5 millones 700 mil seguidores y ha posteado más de 72 mil tweets. Esta fue creada el 31 de octubre de 2020, al parecer manejada por un varón, y se informa sobre nuevos estrenos, nuevas temporadas, y lanzan algunas preguntas a los seguidores; también ofrecen datos de audiencia de las series, como en el presentado en la siguiente imagen, que se refiere a la serie Gambito de Dama, una de las producciones originales de Netflix con mayor audiencia también en México:

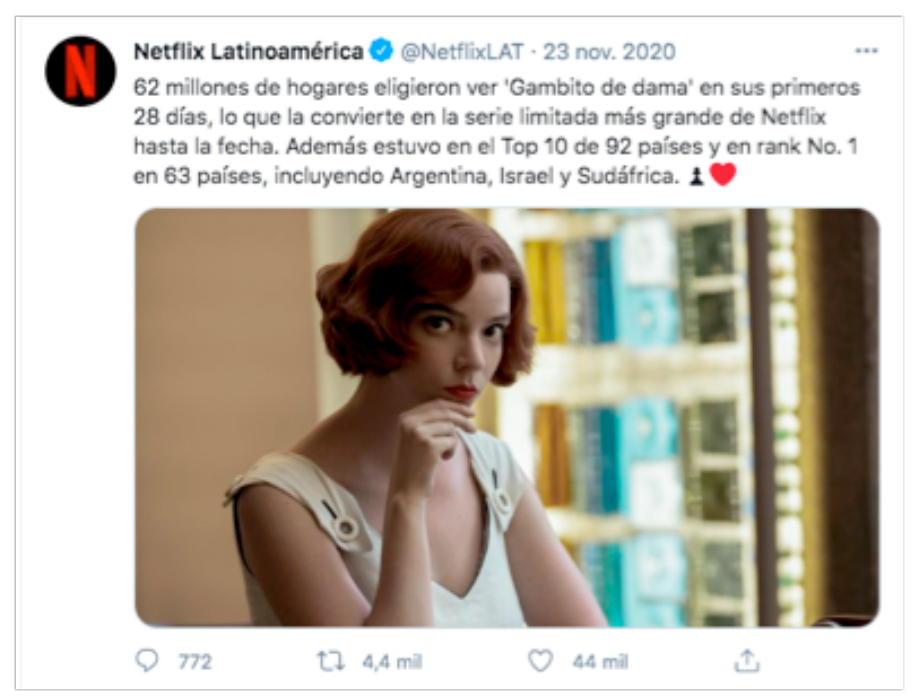

Fuente: https://twitter.com/NetflixLAT 
Netflix también tiene una cuenta en Facebook@Netflixmx con más de 73 millones de seguidores. Por su parte, Amazon Prime Video también promueve contenidos por redes sociales. En Twitter, abrió la cuenta -en noviembre de 2019- y tiene poco más de 199 mil seguidores. En Facebook, @PrimevideoLAT suma más de 15 millones de seguidores. Disney + Latinoamérica (@Disneyplusla) tiene 524 mil seguidores y abrió la cuenta en junio de 2018. En Facebook la cuenta @DisneyPlusLatino tiene poco más de un millón de seguidores.

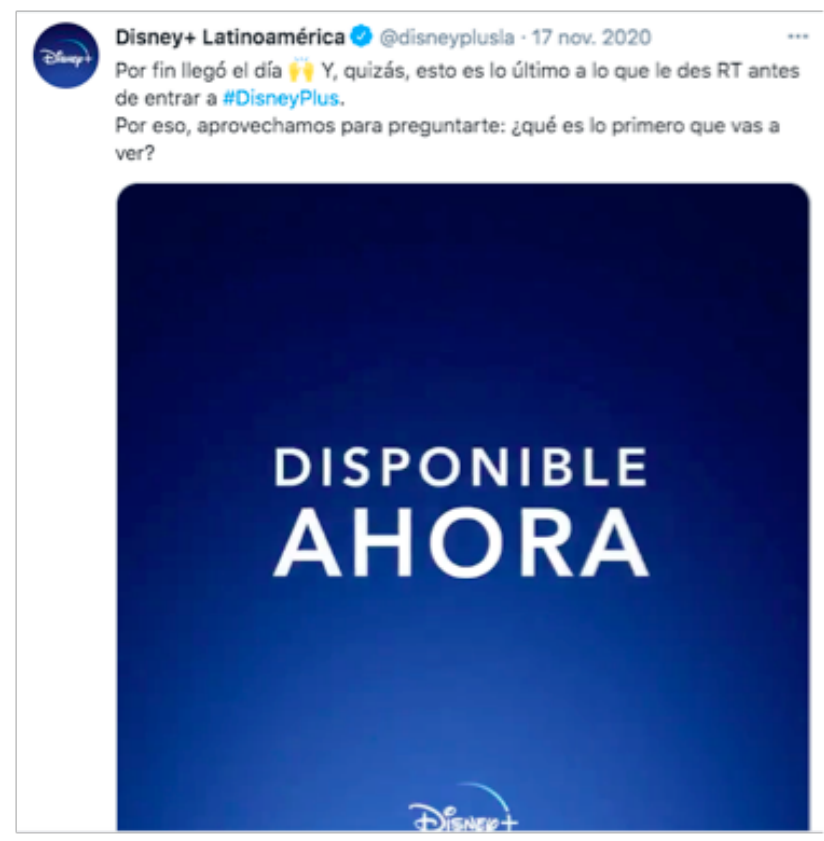

Fuente: @Disneyplusla

A través de las redes sociales digitales la industria de Video on Demand promueve constantemente sus contenidos y mide el termómetro de lo que a la audiencia le va gustando. En América Latina hay más de 60 millones de usuarios de redes sociales digitales. Sin duda es una estrategia de mercado para la promoción de contenidos utilizar estas redes por parte de las plataformas de SVoD. 


\subsection{Interactividad social}

Sin ser necesariamente una ficción, La Más Draga se posicionó como el contenido de paga en YouTube más visto en México por segundo año consecutivo, aunque en 2020 rompió todos los records al ser la producción mexicana más vista del año ${ }^{9}$ en esta plataforma y también se destacó por ser el contenido exclusivo por el que más usuarias y usuarios mexicanos pagaron.

La Más Draga es una serie web de competencia drag producida por La Gran Diabla donde diversas y diversos integrantes de la comunidad LGBTTTQI+ concursan para saber quién realizó la mejor caracterización (vestuario, maquillaje y peinado) de una serie de dinámicas que les son impuestas y que deben ser presentadas en la transmisión en vivo que desde su plataforma se presenta cada martes a las 21 horas.

Esta producción realizó en este 2020 su tercera temporada, la cual ha sido la más exitosa, pues el dinero que se recabó fue utilizado para apoyar a las y los integrantes de la comunidad LGBTTTQI+ que durante la pandemia por COVID-19 perdieron sus trabajos o enfrentaron severos problemas económicos.

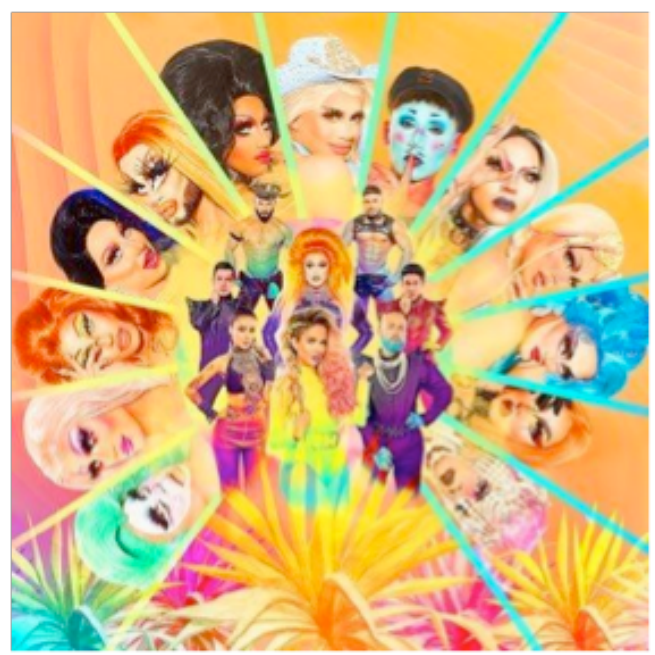

Fuente: La Más Draga 
Lo innovador de este formato es que para ver el contenido "en vivo" o los contenidos exclusivos, se tenía que pagar 99 pesos por emisión (5 usd); estos mismos contenidos días después se subían a su canal de YouTube con una versión editada. De manera extraoficial, la final de la tercera temporada que se realizó el 1 de diciembre de 2020, y logró captar la atención de más de 500 mil usuarios que pagaron por ver la emisión en esa plataforma.

\subsection{Producciones de ficción emergente}

El formato de "contenidos exclusivos" también tuvo su auge con otras y otros creadores de contenido de YouTube, principalmente con cantantes y/o comediantes, quienes también comercializaron en sus canales "lives" (contenidos en vivo) y contenidos especiales, como una forma de hacerse de recursos luego de que se cerraran teatros, centros nocturnos y auditorios.

Así mismo lo hicieron productoras independientes de ficción que aprovecharon el formato de webseries para colocar en YouTube algunas producciones cuyas temáticas giran en torno a la comunidad LGBTTTQI+, lo cual demuestra -como pasó con La Más Draga- la falta de oportunidad y visibilización de otras identidades y orientaciones de género no sólo en la ficción mexicana, sino en la televisión abierta nacional.

Algunas de las webseries de estas temáticas que han sido muy exitosas son La Bastarda y Ana, la Chica Bolera, ambas realizadas no sólo con temática de diversidad de género, sino también actuadas por actrices y actores de la misma comunidad LGBTTTQI+.

Un ejemplo de producción independiente que encontró cobijo en YouTube fueron: $\operatorname{Bravas}^{10}$, una nueva webserie dramática inspirada 
por la música urbana latina que sigue a tres amigas, Mila, Roja y Ashley, que buscan encontrar su lugar en el mundo; y Gris, ${ }^{11}$ que cuenta la historia de Angie y Lara, a quienes la cuarentena las juntó y deben pasar juntas el encierro en un departamento.

\section{Lo más destacado del año}

Aunque el año ha estado marcado, indudablemente, por la pandemia, otro de los grandes temas que padece el país es la violencia, principalmente, la de género, pues conforme a los datos de colectivas feministas como "Nosotras tenemos otros datos" reconocieron al 2020 como "uno de los años más violentos para mujeres y niñas" en México.

En comparación al año anterior, 2019, notaron un incremento del $39 \%$ en solicitud de atenciones y apoyo a la Red Nacional de Refugios (que da seguridad a mujeres que padecen violencia doméstica), que se traduce en 46 mil de mujeres, niñas y adolescentes que fueron víctimas de violencias. Mientras tanto, durante los últimos cuatro meses del 2020, ofrecieron a través de redes sociales, vía telefónica y espacios de protección y atención, 11 mil 132 acompañamientos.

Con ello, identificaron que la gran mayoría de sus agresores, el $75 \%$, eran sus parejas y ex parejas. Lo más preocupante para la Red es que durante noviembre y diciembre del mismo año, una mujer pedía apoyo a la Red Nacional de Refugios, cada hora. Finalmente, cuatro de cada cien mujeres reportó un intento de feminicidio.

Además, coincidieron en que la revictimización por parte de las autoridades es constante y preocupante. Por un lado, violentan continuamente a las mujeres que acuden en busca de apoyo o de denuncia, -quienes ya vienen de situaciones complejas de violencia-. Por el otro, impiden el acceso a la justicia, a los debidos procesos y, 
finalmente, a la detención de sus agresores, lo que significa un círculo de impunidad.

Esta terrible realidad, ahora no fue ajena para las telenovelas mexicanas, tan caracterizadas por obviar este entorno o minimizarlo en sus narrativas, pues una de las telenovelas que más destacó por abordarla fue Vencer al Desamor que plantea este problema a través de la investigación que hace una periodista sobre un feminicida serial. Al final de cada capítulo cada uno de los personajes brindaba algún consejo a la audiencia para que denuncien situaciones de violencia $\mathrm{u}$ otros en caso de vivirlos y se publicaban datos telefónicos de una institución para que la audiencia pudiera solicitar apoyo. Esto a modo de servicio social.

Hay que destacar las dos producciones del llamado proyecto "Vencer", el cual busca tratar temáticas sociales relevantes que ayuden a combatir la violencia de género, así como a empoderar a las audiencias femeninas.

Vencer el Miedo trató sobre las violencias de género que enfrentan en México mujeres de distintas edades, y Vencer el Desamor que buscó desnormalizar las violencias que se justifican a causa del amor de pareja, y también se abordó la violencia de género, lo cual hace evidente que las audiencias mexicanas sí están ávidas de contenidos que aborden esta realidad. Entre 2015 y 2020 el número de víctimas por feminicidio creció cerca de $130 \%$, según datos del Secretariado Ejecutivo del Sistema Nacional de Seguridad Pública ${ }^{12}$.

Ambas ficciones se posicionaron como dos de las diez más vistas del año, siendo mujeres adultas y jóvenes quienes más las consumieron. 


\section{El regreso a la producción de ficción}

TV Azteca había anunciado en 2019 a través de Alberto Ciurana, quien era director general de contenido y distribución de TV Azteca, "descanse en paz la telenovela". Sin embargo, en mayo de 2020 se retractaba anunciando la retransmisión a través de su canal 7 , de la exitosa telenovela Betty, la fea, y el mismo Ciurana mediante un tweet declaraba "y no estaban muertas... andaban de parranda". Al parecer, TV Azteca tiene planeado volver a producir y transmitir telenovelas y series en 2021.

Lamentablemente, este regreso parece no estar presente en otras cadenas como Imagen Televisión o Canal Once que por segundo año consecutivo no producen ningún tipo de serie o telenovela.

\section{El Tema del Año: La Ficción en tiempos de pandemia en México}

En México, se presentó el caso del primer contagio por Covid en febrero de 2020. Desde entonces a la fecha se han infectado más de 2.300.000 personas y han fallecido 212.000 en un país de poco más de 126 millones. El gobierno federal implementó medidas de restricción y cierre de actividades y negocios no esenciales a partir de marzo 26, del 2020. A través del Subsecretario de Salud, el Dr. Hugo LópezGatell, se dieron a conocer las medidas para evitar los contagios, ante la nueva pandemia, conocida como SARS-CoV-2 (Covid).

El cierre de actividades evidentemente afectó también a las empresas productoras de contenidos televisivos, que se vieron forzadas a suspender sus producciones por algunos meses. Nunca se había vivido una situación así a nivel mundial, por lo que esto nos tomó por sorpresa a todos, y tuvimos que adaptarnos a la nueva realidad. Era de esperarse que los efectos de esta pandemia afectaran en todas las áreas de las que dependen las televisoras, principalmente los ingresos publicitarios y la producción de contenidos. 
Costos y pérdidas económicas durante los períodos de confinamiento

En el caso de Televisa, en su reporte de inversión del año 2020, publicado en su portal, $(2021)^{13}$ anunció:

...dado que se consideran actividades económicas esenciales, hemos continuado operando nuestros medios y negocios de telecomunicaciones ininterrumpidos para continuar beneficiando al país con conectividad, entretenimiento e información, y durante el cuarto trimestre finalizado el 31 de diciembre de 2020, continuamos con la producción de nuevo contenido siguiendo los requisitos y pautas de salud impuestas por el gobierno mexicano. Durante el trimestre finalizado el 31 de diciembre de 2020, nuestro negocio de contenido se recuperó de los trimestres anteriores durante la pandemia como resultado de la flexibilización de las restricciones de encierro en algunas jurisdicciones en las que se encuentran los clientes. No obstante lo anterior, somos parcialmente dependientes de la demanda de publicidad de los consumidores empresas, y la pandemia de COVID-19 ha provocado y podría provocar que los anunciantes reduzcan o pospongan su gasto publicitario en nuestras plataformas".

Por su parte, TV Azteca declaró en su reporte del 2020 que "El deterioro de indicadores de la actividad económica derivado de la contingencia sanitaria continuó afectando el dinamismo en el mercado de publicidad en televisión abierta en México, por lo que a pesar de sólidos niveles de audiencia, TV Azteca reportó disminución en ventas netas en el trimestre" $" 14$.

13 https://www.televisair.com/ /media/Files/T/Televisa-IR/documents/annual/2020/ televisa-2020-esp.pdf

14 https://www.irtvazteca.com/documents/es/Downloads/TV-Azteca-Informe-Anual-2020.pdf 
Por lo que estas empresas de televisión tuvieron bajas en sus ingresos por las ventas: Televisa tuvo una caída del 7\% en ganancias, principalmente a causa de los efectos de la pandemia. Debido a que se detuvieron algunos proyectos, y pararon producciones en su totalidad por algunos meses, tuvieron un ahorro en su plan original 2020, en un total de 2.2 billones de pesos. Mientras que TV Azteca, en el año 2020, tuvo una caída del 4\% en sus ventas netas (su venta en 2020: 3.912 millones de pesos; mientras que en 2019: 2.863 millones de pesos).

El rol de las televisoras públicas sobre la pandemia mundial, fue organizar programas informativos sobre el coronavirus, invitando a especialistas que orientaban a la audiencia. En el Canal 11.2 del Instituto Politécnico Nacional se transmiten a la fecha clases en línea "Aprende en Casa por TV" para los niveles básicos (pre-escolar y primaria) de la educación pública en México.

\section{Las producciones de Televisa "pararon"}

Televisa tuvo que detener la producción de ficción, “jamás en mi vida habíamos parado una novela, jamás" declaró la productora de la telenovela de mayor rating en 2020, Te doy la Vida, Lucero Suárez. Las cancelaciones de producciones se dieron en los meses de marzo y abril, regresando a foros en el mes de mayo. Cuando inició el primer brote de coronavirus, la productora Suárez decidió acelerar la producción, añadiendo un día más a las grabaciones (sábados). Para los últimos episodios de la telenovela, las escenas se filmaron con medidas de distanciamiento social, sin besos ni cualquier otro contacto físico.

Otra producción que fue interrumpida por el coronavirus fue el melodrama Imperio de Mentiras, estelarizada por Angelique Boyer, la cual tenía apenas un $20 \%$ de la filmación antes que se detuviera. Esta producción estaba programada para estrenarse a finales de abril, pero inició el 14 de septiembre de 2020. Varios actores estelares de esta producción fueron contagiados, por lo que en un comunicado de 
prensa de octubre de ese año, se informaba del paro de labores en esa telenovela.

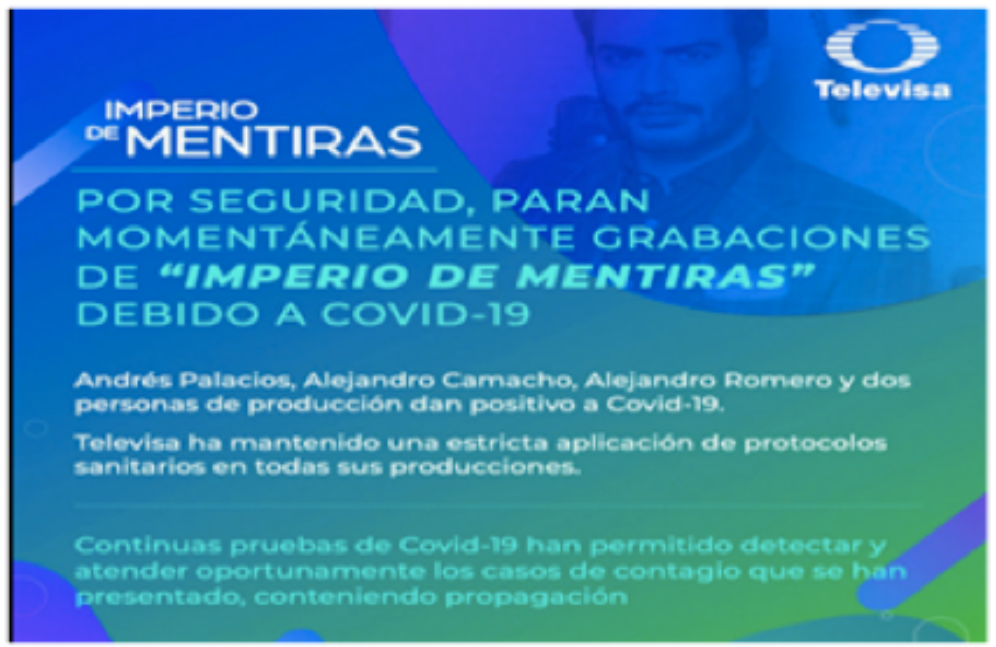

Fuente: https://www.facebook.com/televisaprensamx/

La producción de La Mexicana y el Güero, protagonizada por la actriz Itatí Cantoral también fue afectada. Se aplazó su grabación en el mes de marzo, reanudándose en junio. No se les permitió grabar en las calles, todo tuvo que ser en los foros.

Mientras que el exitoso unitario dramatizado La Rosa de Guadalupe detuvo producciones a partir de que se implementó la medida federal "Sana Distancia" y la orden del paro de labores no esenciales, por lo que detuvo grabaciones en marzo.

\section{Reestrenos para "llenar" espacios}

Debido al paro en la producción de las telenovelas, se decidió retransmitir la bioserie Silvia Pinal, frente a ti, en el horario prime time, en abril de 2020 y Hoy voy a cambiar, biopic sobre la vida de la intérprete Lupita D'Alessio, en mayo. Ese lugar correspondía a la telenovela Imperio de Mentiras, que como comentamos, su producción se detuvo y pudo estrenarse hasta septiembre. 
Por otra parte, el unitario La Rosa de Guadalupe se cambió de horario por unas semanas, y se transmitió una hora adelante de lo habitual, comenzando a las 20:30 horas, antes que iniciaran las transmisiones de Vencer el Desamor. La Rosa de Guadalupe ha cambiado constantemente de horarios desde que apareció por primera vez. Pareciera que dado que es del gusto del público y de la gran cantidad de material que tiene producido, es un programa "comodín" para moverlo según convenga. Este programa transmitió una recopilación de sus mejores episodios, dado que también no pudo estrenar capítulos, por haber parado la producción desde finales de marzo.

Protocolos y estrategias para el retorno de la producción de ficción en la televisión abierta

En el caso de Televisa, se implementaron protocolos para proteger a su personal (producción, actores, etc.). Una de las estrategias para proteger y evitar contagios, fue evitar escenas de amor, pero una telenovela sin escenas de besos no es igual. Según la productora Rosy Ocampo, se implementaron en Televisa códigos de color (desde el verde hasta el rojo). En cuanto al código rojo, estas escenas son las que requerían de algún tipo de cercanía, con actos de pasión y besos, y para poder realizarlos, se les exigía a los actores aplicarse la prueba de Covid. Además, se limpiaba el set como si fuera una sala de operaciones en un hospital, y se permitía menos personal en el foro.

En la telenovela La Mexicana y el Güero, al llegar al set, se les tomaba a los actores la temperatura, y todos debían llevar cubrebocas. En el foro se instalaron tapetes desinfectantes, lavabos portátiles y gel antibacterial. En el área de maquillaje, el personal debía seguir diferentes protocolos de protección, y maquillaban a los actores por turnos.

Mientras que en La Rosa de Guadalupe tuvieron que modificar la logística para movilizar al personal a locaciones, reduciendo los 
espacios en el transporte, lo cual también demoraba todo el proceso de producción; los horarios de grabación son más restringidos (7 de la mañana a 10 de la noche). Cada capítulo de esta ficción se graba en dos días y medio, con dos unidades independientes y equipo asignado a éstas, por lo que pueden grabar cuatro capítulos a la semana. Dada la pandemia, los procesos para preparar las escenas y desinfectar equipo, así como su traslado, obligó a que tuvieran más presión, una vez que reanudaron grabaciones, después de un paro de meses.

\section{Contenidos con el tema de Covid}

En cuanto a que la pandemia fuera abordada en las historias de los melodramas, encontramos que en 2020, solo la Rosa de Guadalupe y Como Dice el Dicho abordaron la problemática, pese a que al inicio de la pandemia habían anunciado sus productores que no abordarían el tema del coronavirus (en el caso de La Rosa de Guadalupe). Sin embargo, en la Rosa de Guadalupe, lo hicieron desde dos aristas: 1) como problema dentro de la historia; algunos de los personajes se contagiaron del Coronavirus y este unitario retrataba las situaciones que padecieron y padecen muchísimas familias al tener un enfermo en casa; 2) Como contexto dentro de la historia: es decir, el epicentro era otra problemática social, pero el Covid formaba parte de lo cotidiano de las vidas de los personajes, de su entorno social. Todos los personajes portaban cubrebocas, o caretas. Capítulos titulados como: Beatriz es atacada con cloro, solo por ser enfermera; La hija de Zoila se contagia de Covid-19; Virus mortal (Coronavirus); Toñito se pone a trabajar durante la pandemia; Aníbal y Sol se convierten en papás en medio de Covid-19; ;Davina sufre por sus clases en línea!

Algunos episodios de la página oficial de La Rosa de Guadalupe, cuentan con más de 6 millones de visualizaciones y el tema abordado en estos deja ver algunas de las situaciones vividas en Méxi- 
co durante la pandemia; como el ataque a personal médico por parte de ciudadanos; o las difíciles condiciones de una enorme mayoría de la población en México, como las que viven los estudiantes que cursan sus clases en línea. Como sello característico de este unitario, la solución se centra en el milagro y la fe, y la intercesión de la Virgen de Guadalupe para la solución de los problemas. Para su director de escena, Eduardo Said, el éxito de este unitario se debe a que existe una empatía con el público "para que las personas que la vemos nos reconozcamos en lo que ahí sucede y en las personas que están ahí y entonces permanezcamos en la pantalla y la gente diga 'claro esto me ha pasado o le ha pasado a alguien que conozco, y puedo aprender de ello". ${ }^{15}$ No podemos dejar de mencionar a Martín-Barbero, quien en el libro De los medios a las mediaciones reflexionaba precisamente este punto del reconocimiento.

Otra de las producciones de Televisa donde se abordó el tema de la pandemia, fue el unitario Como dice el dicho. En esta serie se narra una historia donde se selecciona un "dicho" y el programa es protagonizado por uno de los actores cómicos más reconocidos en México, Sergio Corona. Algunos de los títulos de sus episodios son: Almendrita se contagia ante la imprudencia de sus hermanas; Daniela hace compras de pánico por la cuarentena; La medicina cura y el amor sana; Dany sufre un ataque de pánico por las noticias de Covid;

En la producción de Vivir el desamor, no fue tema de la historia el Covid, ni los personajes portaban máscaras protectoras, sin embargo, en el cierre musical de la telenovela cuando aparecen los créditos, aparecían escenas con los miembros de la producción en acción en el set, portando cubrebocas. En uno de los capítulos, el personaje principal, interpretado por la actriz Daniela Romo, se dirige a la audiencia explicando la salida de un actor (Leonardo Daniel) de la producción, debido a que había sido contagiado de Covid. La actriz informó el nombre del actor que lo reemplazaría. 


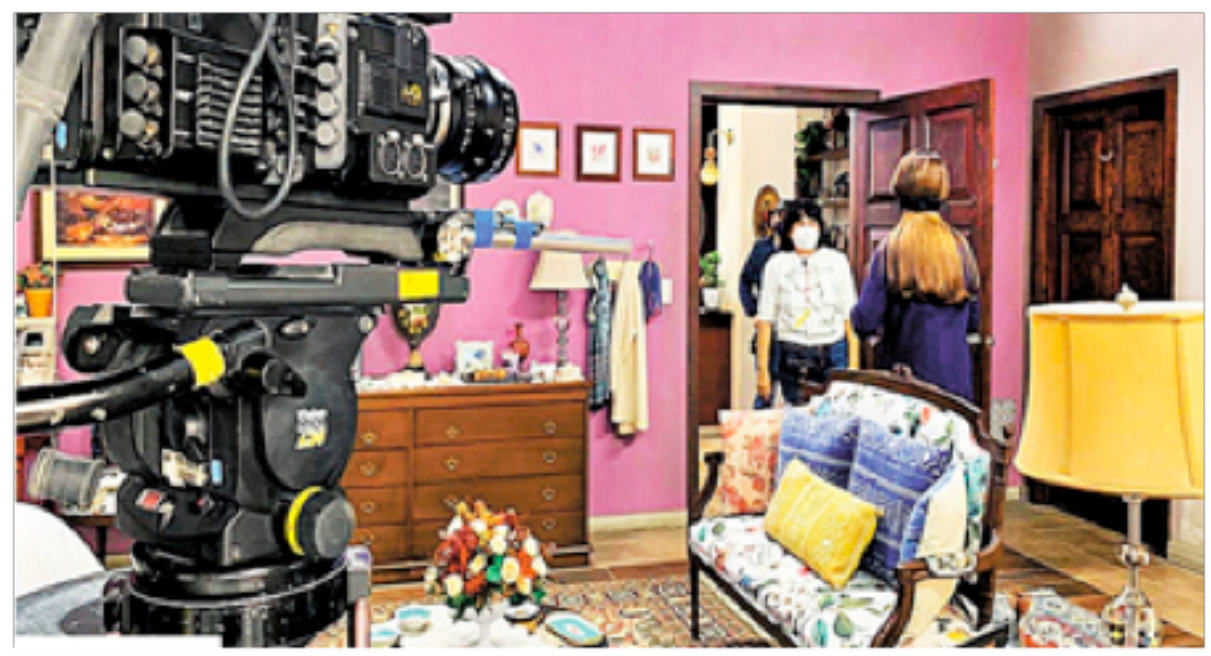

Imagen: Escena de Vivir el desamor (2020).

Fuente: https://www.milenio.com/espectaculos/television/rosy-ocampo-telenovela-concientiza-cambia-habitos

En el resto de las telenovelas de 2020 el tema de Covid no apareció en los contenidos. Sin embargo, a inicios de 2021, se lanzó la nueva producción de Juan Osorio, precisamente en el horario que dejó Vivir el Desamor. La telenovela producida por él, ¿Qué le pasa a mi familia? abordó el problema de la pandemia por Covid-19, y se supo que tuvo una advertencia que sería castigado, de parte de las altas esferas de Televisa, por haber hablado del tema en esa telenovela.

La advertencia fue por no haber avisado a la empresa que trataría este tema: El productor declaró que: “A veces nos cuesta trabajo tener que aceptar la realidad, pero ni modo, no es un problema de mi país, es un problema mundial y eso tenemos que tocarlo, nos guste o no". ${ }^{16}$

$16 \mathrm{https} / /$ www.milenio.com/espectaculos/famosos/juan-osorio-televisa-castigo-hablarcovid19-novela-video 
Algunas reflexiones

Por lo que podemos ver, la única empresa televisiva en México que produce telenovelas en el país es Televisa, en 2020. Pero la pandemia afectó a todas las televisoras y todas tuvieron pérdidas por concepto de publicidad. TV Azteca apenas anunció su retorno a la ficción y lo hizo con el reestreno de Lo que Callamos las Mujeres, lo cual reportaremos en el anuario 2021, e Imagen TV sigue comprando telenovelas producidas en otros países (telenovelas turcas) y retransmitiendo bioseries, como Paquita la del Barrio. Ante los enormes retos que impuso la pandemia por Covid-19, Televisa tuvo que detener sus producciones, para proteger a su personal pero también para acatar las medidas federales. Nunca en su historia había acontecido un evento de tal naturaleza. Haciendo un balance, podemos decir que ganó audiencia en televisión abierta; los reportes de rating para este año indican al menos que el primer lugar (dentro de los top ten de ficción) con mayor audiencia en televisión abierta, en 2020 obtuvo un punto más que la reportada en el mismo sitio en el año 2019. Los dramatizados unitarios siguen a la alza en Televisa. En el caso de La Rosa de Guadalupe se mantiene como una de las ficciones más exitosas de todos los tiempos, con un promedio de 17 puntos rating, mientras que como Como dice el Dicho obtuvo 16,22 puntos, casi un punto más que en 2019. Estas dos producciones fueron las únicas en 2020 en abordar el tema de Covid-19. Televisa dejó fuera de los contenidos del melodrama tradicional (telenovelas) a la pandemia. ¿Qué dice esto al respecto? ¿Por qué decidió no abordar este tema en sus historias? 
Creemos que ha sido consistente a su filosofía de "entretener" a la audiencia. Si bien, en varias producciones, como lo hemos reportado, abordan casos que tienen que ver con problemas sociales, en el caso de la pandemia es un dato revelador que no se haya insertado en las historias. Consideramos que el público vive una gran incertidumbre ante un evento único e inesperado, totalmente nuevo, y recibe mucha información por parte de los medios de comunicación (incluidas las redes sociales) que le saturan. Mucha de esta información es negativa, o falsa. Quizá las cabezas de Televisa decidieron no llenar con más contenidos sobre la pandemia en las telenovelas, y darle un "respiro" a la audiencia ante lo que se vive.

Solo los unitarios La Rosa de Guadalupe y Como Dice el Dicho abordaron el tema de Covid-19, y como mencionamos, apenas en 2021 uno de los más exitosos productores, Juan Osorio, se atrevió a abordar la problemática en una telenovela. A diferencia de otros países en que las televisoras apostaron por producir contenidos de ficción que abordaron la pandemia, Televisa no, ni las otras televisoras privadas y públicas.

Todas las televisoras privadas han tenido enormes pérdidas económicas, mientras que las plataformas de SVoD duplicaron suscriptores y comenzaron a incluir en sus catálogos, más telenovelas. Como en el caso de Netflix, que incluyó en 2020 la exitosa telenovela 100 días para Enamorarnos, producida por Telemundo (Estados Unidos) y que quedó a la mitad de las grabaciones cuando apareció la pandemia y retomó la producción meses después. Esto indica que las plataformas como Netflix conocen bien que este género es del gusto de las audiencias. Lanzando todos los capítulos, sin que la audiencia tenga que esperar como lo hace en la televisión lineal para consumir el contenido con la flexibilidad que las plataformas permiten. 
A manera de cierre

Sin duda, la pandemia y más de un año de encierro en casa trajeron consigo nuevas prácticas mediáticas que difícilmente cambiarán y que, sin duda alguna, han modificado de manera profunda tanto a la industria de la informática como a la del entretenimiento; por ejemplo, la serie de actividades que podemos resolver a través de una mediación tecnológica; aprendimos que podemos reunirnos con otras y otros para resolver o acordar cosas sin tener que vernos presencialmente, pero principalmente, aprendimos que todo el entretenimiento puede quedarse en casa y así lo comprueba el incremento de las plataformas y sistemas de VoD durante la pandemia.

Esta predominancia, empujada por la pandemia, ha creado un reajuste en las industrias del entretenimiento, pues quien no se inserta en este nuevo mercado estará destinado a morir; por ello, este capítulo queremos cerrarlo con la fusión en servicios de streaming entre Televisa (México) y Univisión (Estados Unidos), anunciado el 13 de abril de 2021, para crear lo que llamaron el sistema de medios en español más importante del mundo.

Esto, consideramos, marcará la agenda de la producción televisiva en Iberoamérica en los próximos años, pues es una apuesta por competir -desde el ámbito iberoamericano- con los dueños del streaming: Netflix, Amazon y ahora Disney+, entre otros más. 


\section{Referencias}

The Global Television Demand Report 2020. Parrot Analytics.

Zepeda, L. (2021, marzo 1). Defensoras presentan radiografía sobre la violencia contra las mujeres en México. https:/www.zonadocs.mx/2021/03/01/ defensoras-presentan-radiografia-sobre-la-violencia-contra-las-mujeres-en-mexico/ 